\title{
JEJARING SOSIAL dan DAMPAK BAGI PENGGUNANYA
}

\author{
Abdillah Yafi Aljawiy ${ }^{1}$, Ahmad Muklason ${ }^{2}$ \\ Jurusan Sistem Informasi, Fakultas Teknologi Infomasi \\ Institut Teknologi Sepuluh Nopember \\ Jl. Raya ITS Kampus ITS Sukolilo Surabaya Indonesia 60111 \\ yape@is.its.ac.id ${ }^{1}$, mukhlason@is.its.ac.id $^{2}$
}

\begin{abstract}
Abstraksi
Akhir-akhir ini istilah situs jejaring sosial sangat akrab di telinga kita. Bahkan mungkin hampir setiap orang menggunakan situs jejaring sosial ini termasuk mahasiswa. Di dalam jejaring sosial ini para mahasiswa dapat bersosialisasi dengan berbagai orang di dunia maya. Bahkan dapat pula dijadikan media bisnis. Namun jejaring sosial juga memiliki dampak positif dan buruk bagai penggunanya. Mengapa bisa terjadi hal seperti ini memang menjadi pertanyaan yang cukup besar. Oleh karena itu saya akan membahasnya di dalam paper ini.
\end{abstract}

\section{Keywords: Jejaring Sosial; kehidupan sosial; teknologi}

\section{PENDAHULUAN}

Belakangan ini situs jejaring sosial sangat marak perkembangannya di sekitar kita. Bahkan penggunanya sangat banyak dan meliputi hampir berbagai kalangan usia mulai dari anak-anak, remaja, dan orang dewasa.

Jejaring sosial sendiri mempunyai arti sebagai struktur sosial yang terdiri dari elemen-elemen individual atau organisasi. Jejaring ini menunjukan jalan dimana mereka berhubungan karena kesamaan sosialitas, mulai dari mereka yang dikenal sehari-hari sampai dengan keluarga.[11]

Analisis jaringan sosial memandang hubungan sosial sebagai simpul dan ikatan. Simpul adalah aktor individu di dalam jaringan, sedangkan ikatan adalah hubungan antar aktor tersebut. Bisa terdapat banyak jenis ikatan antar simpul. Penelitian dalam berbagai bidang akademik telah menunjukkan bahwa jaringan sosial beroperasi pada banyak tingkatan, mulai dari keluarga hingga negara, dan memegang peranan penting dalam menentukan cara memecahkan masalah, menjalankan organisasi, serta derajat keberhasilan seorang individu dalam mencapai tujuannya.

Dalam bentuk yang paling sederhana, suatu jaringan sosial adalah peta semua ikatan yang relevan antar simpul yang dikaji. Jaringan tersebut dapat pula digunakan untuk menentukan modal sosial aktor individu. Konsep ini sering digambarkan dalam diagram jaringan sosial yang mewujudkan simpul sebagai titik dan ikatan sebagai garis penghubungnya.[12]

Banyak manfaat yang kita dapat dari jejaring sosial. Selain jangkauannya tidak terbatas sehingga kita bisa berkomunikasi dengan siapa saja di mana saja, jejaring sosial juga biasa dimanfaatkan untuk kontrol sosial masyarakat terhadap pemerintah.

Selain keuntungan jejaring sosial tentunya juga mempunyai beberapa kerugian atau dampak negative. Misalnya seperti penipuan, pornografi, bahkan penculikan. Seperti berita yang pernah terkabarkan bahwa MUI mengharamkan facebook, itu adalah salah satu dampak akibat ulah beberapa orang yang menyalahgunakan facebook sehingga jejaring sosial menjadi suatu hal yang buruk dan tidak pantas untuk masyarakat umum. Padahal banyak sekali manfaat yang bisa didapat melalui jejaring sosial.

\section{SITUS JEJARING SOSIAL}


Situs jejaring sosial (bahasa Inggris: Social network sites) merupakan sebuah web berbasis pelayanan yang memungkinkan penggunanya untuk membuat profil, melihat list pengguna yang tersedia, serta mengundang atau menerima teman untuk bergabung dalam situs tersebut.[1] Tampilan dasar situs jejaring sosial ini menampilkan halaman profil pengguna, yang di dalamnya terdiri dari identitas diri dan foto pengguna.[2]

\section{SEJARAH SITUS JEJARING SOSIAL}

Kemunculan situs jejaring sosial ini diawali dari adanya inisiatif untuk menghubungkan orang-orang dari seluruh belahan dunia.[3]

Sejak komputer dapat dihubungkan satu dengan lainnya dengan adanya internet banyak upaya awal untuk mendukung jejaring sosial melalui komunikasi antar komputer. Situs jejaring sosial diawali oleh Classmates.com pada tahun 1995 yang berfokus pada hubungan antar mantan teman sekolah dan SixDegrees.com pada tahun 1997 yang membuat ikatan tidak langsung.[1]

Dua model berbeda dari jejaring sosial yang lahir sekitar pada tahun 1999 adalah berbasiskan kepercayaan yang dikembangkan oleh Epinions.com, dan jejaring sosial yang berbasiskan pertemanan seperti yang dikembangkan oleh Uskup Jonathan yang kemudian dipakai pada beberapa situs UK regional di antara 1999 dan 2001.[1] Inovasi meliputi tidak hanya memperlihatkan siapa berteman dengan siapa, tetapi memberikan pengguna kontrol yang lebih akan isi dan hubungan. Tahun 2001, muncul Ryze.com yang berperan untuk memperbesar jejaring bisnis.[1]

Tahun 2002, muncul friendster sebagai situs anak muda pertama yang semula disediakan untuk tempat pencarian jodoh.[4] Dalam keanjutannya, friendster ini lebih diminati anak muda untuk saling berkenalan dengan pengguna lain.[4] Tahun 2003, muncul situs sosial interaktif lain menyusul kemunculan friendster, Flick R, You Tube, Myspace.[1] Hingga akhir tahun 2005, friendster dan Myspace merupakan situs jejaring sosial yang paling diminati.

Booming Friendster.com di kalangan pelajar dan mahasiswa pada empat tahun terakhir, telah menempatkan Indonesia sebagai pemilik account Friendster nomor tiga sedunia. Melihat tren penghujung tahun 2008, ada kemungkinan layanan social networking akan sedikit bergeser ke Facebook.com. Brand Facebook yang lebih dewasa dan lebih kaya dengan aplikasi, membawa tantangan baru bagi mantan maniak Friendster untuk lebih banyak ber-eksperimen.

Facebook yang didirikan tahun 2004, telah mencatatkan lebih dari 37 juta pengguna serta ribuan jaringan bisnis. Facebook dibuat oleh alumni Universitas Harvard, Mark Zuckenberg awalnya hanya sebatas situs untuk para alumni lulusan Harvard. Selanjutnya Facebook berkembang pesat sebagai situs untuk hiburan dan pekerjaan. Facebook memiliki layanan fitur privasi. Dengan layanan para pengguna Facebook dapat mengontrol terhadap siapa saja yang diperbolehkan mengakses data profil mereka.

Facebook telah mengembangkan berbagai ragam aplikasi yang dapat diinstall para pengguna. Aplikasi-aplikasi inilah yang memberikan nilai tambah bagi Facebook. Aplikasi yang dikembangkan banyak yang mendukung bisnis dan pekerjaan seperti menjual atau membeli barang, ala eBay dengan orang-orang yang ada dalam jaringan yang dimiliki para pengguna. Dengan situs 
web tersebut kita dapat bergabung dengan komunitas pengguna situs tersebut. Mungkin sebagian besar pengguna komunitas yang kita kunjungi adalah rekan-rekan kita atau bisa jadi teman baru yang kita kenal di dunia "maya". Ibaratnya bagaikan suatu ruangan yang sangat luas di "dunia internet", tempat berkumpul banyak orang yang sudah kita kenal atau barangkali ingin kita kenal. Kita juga bisa "mengundang" orang-orang yang kita kenal tapi belum tergabung dengan komunitas jejaring sosial tersebut untuk ikut bergabung.[2] Tahun 2009, kemunculan Twitter ternyata menambah jumlah situs sosial bagi anak muda.[1] Twitter menggunakan sistem mengikuti - tidak mengikuti (follow-unfollow), dimana kita dapat melihat status terbaru dari orang yang kita ikuti (follow).[1]

Pada awalnya situs-situs jejaring sosial isinya lebih banyak terkait hal-hal yang sifatnya "fun" dan nostalgia ria tapi selanjutnya terjadi perkembangan yang mengarah ke arah profesionalisme. Dari sekedar komunitas biasa/pertemanan, lalu bertransformasi menjadi tempat untuk melakukan kontak bisnis atau komunitas yang lebih serius. Para pengguna mulai memanfaatkan situs-situs jejaring sosial sebagai alat yang mendukung profesi ataupun wirausaha. Info kontak person dapat membantu menemukan beragam rute dan informasi menuju jenis perusahaan yang diinginkan ataupun peluang bisnis baru. Para pengguna situs jejaring sosial pun mulai bergeser, tidak hanya didominasi oleh generasi muda atau remaja, golongan tua pun sudah mulai melirik situs jejaring sosial sebagai tempat favorit bersosialisasi.

\section{MACAM-MaCAM SituS JeJARING SOSIAL}

Terdapat ratusan situs jejaring sosial di berbagai belahan dunia yang sengaja dibuat untuk menghubungkan orang-orang dalam berinteraksi satu sama lain.[5] Berikut adalah daftar beberapa diantaranya.

\subsection{Facebook}

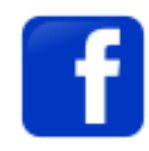

Gambar 1. Logo Facebook

Facebook merupakan situs jejaring sosial yang aplikatif.[2] Facebook menyajikan gambaran akan hal-hal yang menarik, adanya pemberitahuan baru atau notifikasi, ruang untuk mengobrol langsung (chatting), unggah foto/video, dan mengirimkan pesan kepada pengguna lain di saat pengguna lain tersebut sedang diluar jaringan (offline).[6]

\subsection{YouTube}

\section{You Tube}

Gambar 1. Logo Youtube

YouTube merupakan situs yang lebih dikenal untuk menampilkan video dimana masyarakat umum dapat mengunduh atau mengunggah video mereka masing-masing.[7] Dalam You Tube dikenal dua istilah, yaitu publicly private dan privately public.[7]

\section{Publicly private}

Berarti video tersebut tidak dapat diakses secara bebas oleh publik, akan tetapi identitas pembuat video disampaikan.[7] Agar video tersebut hanya dapat diakses oleh orang tertentu, 
pembuat video dapat membuat video tersebut terbatas untuk teman-temannya saja (friendsonly) atau dengan tidak memberikan fasilitas tag.[7]

2. Privately public

Berarti video tersebut dapat diakses secara bebas oleh publik tertentu maupun publik luas, akan tetapi identitas pembuat video dirahasiakan.[7] Ini karena pembuat video tidak menginginkan identitasnya diketahui, oleh karena itu pembuat video seringkali menggunakan nama alias tertentu.[7]

Yои Tube juga memiliki halaman profil yang memungkinkan kita untuk saling berinteraksi atau meninggalkan komentar atas video yang kita lihat, yang disebut dengan channel page.[7] Apabila komentar tersebut dibaca oleh pembuat video, kita dapat berinteraksi langsung dengannya.[7]

\subsection{Twitter}

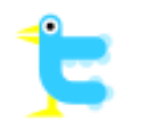

Gambar 2. Logo Twitter

Merupakan situs sosial yang saat ini menduduki peringkat pertama dengan menggunakan sistem satu arah.[8] Dengan menekan tombol follow, kita dapat melihat pembaharuan (update) status dari mereka yang kita ikuti (follow).[7]

\subsection{Friendster}

Friendster merupakan situs yang dibuat pada tahun 2002 yang semula dimaksudkan untuk situs pencarian jodoh dan memperbesar jaringan bisnis.[8] Dalam kelanjutannya, friendster lebih sering digunakan oleh anak-anak muda untuk berhubungan dengan orang-orang baru.[8]

\subsection{Myspace}

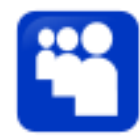

Gambar 3. Logo Myspace

Myspace merupakan situs sosial yang menskonsentrasikan layanannya di bidang musik.[8]Kehadiran Myspace tahun 2003 memunculkan tampilan foto, profil, grup, chatting, dan layanan unggah (upload) lagu / video.[8] Myspace juga menyediakan layanan pemasangan genre musik khusus pada halaman profil..[8]

\subsection{FlickR}

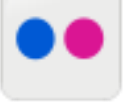

Gambar 4. Logo FlickR

FlickR adalah situs yang memungkinkan penggunanya untuk menampilkan foto dan video.[7] Pengunjung situs dapat melihat video atau foto-foto yang baru di unggah oleh pengguna-pengguna lain dari seluruh belahan dunia melalui situs tersebut.[8] 


\section{DAMPAK PENGGUNAAN JEJARING SOSIAL}

Jejaring sosial memiliki dampak tersendiri bagi para penggunanya.

\subsection{Dampak positif}

Dampak positif yang timbul dari penggunaan situs jejaring sosial adalah sebagai berikut

1. Semakin Mudahnya Berinteraksi dengan Orang Lain

Karena dapat berkomunikasi secara livetime, Para pengguna jejaring sosial dapat dengan mudah berinteraksi dengan orang lain. Bahkan tak lagi terpengaruh oleh jarak yang sangat jauh. Selain itu, dengan adanya situs jejaring sosial, penyebaran informasi dapat berlangsung secara cepat.[9]

\section{Sarana Promosi}

Kunggulan lainnya media ini dapat digunakan sebagai sarana promosi suatu barang, komunitas, band dan lain-lain.[13]

3. Sarana Sosialisasi Program Pemerintah

Di negara Indonesia, pemerintah banyak melakukan sosialisasi dalam berbagai hal pendidikan, kesehatan, politik, penanggulangan bencana, ekonomi, dan informasi yang lain. Selain menggunakan media cetak, pemerintah mensosialisasikan programnya melalui situs jejaring sosial. Salah satu contohnya yaitu kampanye dalam pemilu 2009.[13]

4. Sarana Silaturahmi

Tak dapat dipungkiri jika jejaring sosial merupakan sarana paling efektif untuk menjalin Komunikasi dan Silaturahmi dengan teman, sahabat maupun keluarga. Tanpa lagi dibatasi jarak, tempat dan waktu, anda bisa terus menjalin silaturahmi dengan mereka, berbagi pengalaman bahkan anda bisa merencanakan sebuah acara pertemuan keluarga dengan mereka.

5. Sarana Hiburan

Para pengguna bisa bersenang-senang dan bergaul dengan orang dari seluruh penjuru dunia. Dengan perkembangan pesat dunia internet, maka sarana dan prasarana untuk bisa bersenangsenang dan bergaul di online social networking pun semakin banyak pilihan. Dari mulai maen game dengan teman virtual anda, sampai kepada saling kirim kartu ucapan.

\subsection{Dampak Negatif}

1. Kurangnya Interaksi dengan Dunia Luar

Kemunculan situs jejaring sosial ini menyebabkan interaksi interpersonal secara tatap muka (face-to-face) cenderung menurun.[10] Orang lebih memilih untuk menggunakan situs jejaring sosial karena lebih praktis.[10] Hal ini menyebabkan orang tersebut menjadi anti-sosial.

3. Membuat Kecanduan

Tidak dapat dipungkiri jika para pengguna jejaring sosial dapat menghabiskan waktunya seharian d depan komputer karena kecanduan. Sehingga membuat produktifitas menjadi menurun karena sebagian besar waktunya hanya digunakan untuk jejaring sosial.[3]

4. Pemborosan

Tidak sedikit biaya yang dikeluarkan orang tersebut tidaklah sedikit untuk mengaktifkan internet atau membayar warnet. Hal ini tentu saja akan merugikan bagi penggunanya sendiri karena tidak sedikit biaya yang terbuang sia-sia karena hanya sekedar menggunakan jejaring sosial.

5. Tergantikannya kehidupan sosial 
Jejaring sosial sangat nyaman sekali digunakan. Saking nyamannya sebagian orang merasa cukup dengan berinteraksi lewat jejaring sosial saja sehingga mengurangi frekuensi tatap muka dengan orang lain. Bertatap muka tidak seharusnya digantikan dengan bertemu di dunia maya. Obrolan, tatapan mata, ekspresi muka, dan canda lewat ketawa tidak bisa tergantikan oleh rentetan kata-kata bahkan video sekalipun. Tentunya ada sebuah hal yang hilang dari interaksi seperti ini.

6. Pornografi

Sebagaimana situs jejaring sosial lainnya, tentu ada saja yang menyalahgunakan pemanfaatan dari situs tersebut untuk kegiatan yang berbau pornografi. Bahkan ada yang memanfaatkan situs semacam ini untuk menjual wanita.

7. Kesalahpahaman

Di jejaring sosial Facebook, pernah ada kasus pemecatan seorang karyawan karena menulis yang tidak semestinya di Facebook. Bahkan juga pernah terjadi penuntutan ke meja pengadilan karena kesalahpahaman di Facebook. Jejaring sosial Facebook ini merupakan jaringan sosial yang sifatnya terbuka antara user dan teman-temannya. Seperti kehidupan nyata, gossip, atau informasi miring dengan cepat juga dapat berkembang di jaringan ini. Haruslah disadari menulis di status, di wall dan komentar diberbagai aplikasi adalah sama saja seperti obrolan pada kehidupan nyata bahkan efeknya mungkin lebih parah karena bahasa tulisan terkadang menimbulkan salah tafsir.[13]

8. Berkurangnya Perhatian Terhadap Keluarga

Hal ini mungkin tanpa kita sadari terjadi jika kita membuka facebook saat sedang bersama keluarga. Sebuah riset di inggris menunjukan bahwa orang tua semakin sedikit waktunya dengan anak-anak mereka karena berbagai alasan. Salah satunya karena Facebook. Bisa terjadi sang suami sedang menulis wall, si istri sedang membuat koment di foto sementara anaknya diurusi pembantu.[13]

9. Sarana Kriminal

Tentunya para pengguna jejaring sosial harus waspada karena banyak orang-orang tak bertanggung jawab yang menggunakan jejaring sosial untuk melancarkan aksinya. Seperti kasus penculikan beberapa waktu lalu yang terjadi karena korban diajak bertemu di suatu tempat setelah sebelumnya berkenalan di dalam jejaring sosial. Selain itu juga banyak terjadi kasuskasus penipuan di dalam jejaring sosial.

10. Mempengaruhi kesehatan (masih perdebatan.

Sebuah artikel di media inggris menyebutkan Facebook dapat meningkatkan stroke dan penyakit lainnya. Namun alasan tersebut masih diperdebatkan oleh banyak ahli.[13]

\section{DAMPAK PENGGUNAAN JEJARING SOSIAL}

Menurut saya pribadi, kehadiran dari jejaring sosial ini sendiri sangat bermanfaat. Terlebih karena saya jauh dari keluarga, dengan adanya jejaring sosial ini saya mampu untuk berhubungan dengan keluarga lewat dunia maya. Selain itu saya juga dapat berhubungan dengan teman-teman lama saya. Setidaknya menjalin kembali silaturahmi yang sempat putus karena kuliah di beberapa tempat yang berbeda.

Dampak baik atau buruk dari jejaring sosial itu tergantung dari kemampuan seseorang mengatur dirinya. Jika tidak digunakan secara berlebihan tentu tidak akan merugikan penggunanya sendiri dan tentu saja para pengguna harus lebih berhati-hati dalam menggunakannya agar tidak menjadi korban kriminalitas. 
Oleh karena itu sebaiknya mulai saat ini kita lebih memahami dan menggunakan jejaring sosial dengan baik dan tidak menyalahgunakannya. Akan lebih baik lagi kalau kita bisa memberi penyuluhan tentang jejaring sosial kepada orang tua agar mereka dapat mengawasi anak-anak mereka yang berusia dibawah umur untuk tidak terjerumus oleh jejaring sosial.[13]

\section{REFERENCES}

1. Social Network Sites: Definition, History, and Scholarship. Journal of Computer-Mediated Communication, 13(1), article 11.

2. Setiawan, Dirgayuza. 2008. Gaul Ala Facebook untuk Pemula. Jakarta: Media Kita. Hal 6-9.

3. Watkins, S.Craig. 2009. The Young and the Digital: What the Migration to Social Network Sites, Games, and Anytime, Anywhere Media Means for Our Future.'UK: Beacon Press.

4. Lange, P. G. (2007). Publicly private and privately public: Social networking on YouTube. Journal of Computer-Mediated Communication, 13(1), article 18.

5. Lange, P. G. (2007). Publicly private and privately public: Social networking on YouTube. Journal of Computer-Mediated Communication, 13(1), article 18.

6. Rafiudin, Rahmat. 2008. Kupas Tuntas Aplikasi Facebook Terpopuler. Jakarta: PT.Elex Media Komputindo. Hal 69\&95-96.

7. Lange, P. G. (2007). Publicly private and privately public: Social networking on YouTube. Journal of Computer-Mediated Communication, 13(1), article 18.

8. Social Network Sites: Definition, History, and Scholarship. Journal of Computer-Mediated Communication, 13(1), article 11.

9. Lin, Carolyn A. \& Atkin, David A. 2002. Communication Technology and Society. Cresskill, NJ: Hampton Press, Inc. Hal 183.

10. Watkins, S.Craig. 2009. The Young and the Digital: What the Migration to Social Network Sites, Games, and Anytime, Anywhere Media Means for Our Future.'UK: Beacon Press.

11. http://blog.ub.ac.id/ollabonita/2010/04/06/social-networking-dalam-kehidupan/

12. http://id.wikipedia.org

13. http://gmild.wordpress.com/2009/11/04/situs-jejaring-sosial-social-networking/

14. http://kaskus.us

15. J. Breckling, Ed., The Analysis of Directional Time Series: Applications to Wind Speed and Direction, ser. Lecture Notes in Statistics. Berlin, Germany: Springer, 1989, vol. 61.

16. S. Zhang, C. Zhu, J. K. O. Sin, and P. K. T. Mok, "A novel ultrathin elevated channel lowtemperature poly-Si TFT," IEEE Electron Device Lett., vol. 20, pp. 569-571, Nov. 1999.

17. M.Wegmuller, J. P. von der Weid, P. Oberson, and N. Gisin, "High resolution fiber distributed measurements with coherent OFDR," in Proc. ECOC'00, 2000, paper 11.3.4, p. 109.

18. R. E. Sorace, V. S. Reinhardt, and S. A. Vaughn, "High-speed digital-to-RF converter," U.S. Patent 5668 842, Sept. 16, 1997.

19. (2002) The IEEE website. [Online]. Available: http://www.ieee.org/

20. M.Shell. (2002) IEEEtran homepage on CTAN. [Online]. Available: http://www.ctan.org/texarchive/macros/latex/contrib/supported/IEEEtran/

21. FLEXChip Signal Processor (MC68175/D), Motorola, 1996.

22. "PDCA12-70 data sheet," Opto Speed SA, Mezzovico, Switzerland.

23. A. Karnik, "Performance of TCP congestion control with rate feedback: TCP/ABR and rate adaptive TCP/IP," M. Eng. thesis, Indian Institute of Science, Bangalore, India, Jan. 1999.

24. J. Padhye, V. Firoiu, and D. Towsley, "A stochastic model of TCP Reno congestion avoidance and control," Univ. of Massachusetts, Amherst, MA, CMPSCI Tech. Rep. 99-02, 1999.

Wireless LAN Medium Access Control (MAC) and Physical Layer (PHY) Specification, IEEE Std. 802.11, 1997. 